
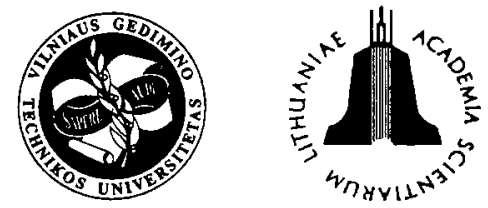

ISSN $1392-3730$

JOURNAL OF CIVIL ENGINEERING AND MANAGEMENT

http:/www.vtu.lt/english/editions

2003, Vol IX, No l, 3-9

\title{
INVESTIGATION OF AUTOMOBILE ROADS PAVEMENT DETERIORATION TRENDS IN LITHUANIA
}

\author{
Aivaras Braga', Virgaudas Puodžiukas ${ }^{2}$, Donatas Čygas ${ }^{3}$, Alfredas Laurinavičius ${ }^{4}$ \\ 1. 3,4 Dept of Roads, Vilnius Gediminas Technical University, Sauletekio al. 11, LT-2040 Vilnius, Lithuania \\ 1E-mail:braga@centras.lt; ${ }^{3}$ E-mail:dcyg@ap.vtu.lt; ${ }^{4} E$-mail: alfla@ap.vtu.lt \\ ${ }^{2}$ Lithuaniant Road Administration, J.Basanaviciaus g. 36/2, LT-2009 Vilnius, Lithuania \\ 2 E-mail:vpuodziukas@lra.lt;
}

Received 17 Oct 2002; accepted 15 Dec 2002

\begin{abstract}
Currently there are three pavement management systems (PMS) used in Lithuania for planning and management of road maintenance and repair activities: HDM-III, HDM-4 and DAVASEMA (Lithuanian PMS). HDM pavement deterioration models are used in all of them. With the purpose of calibration and adaptation of those models in 1997 Lithuanian Pavement Deterioration Research Project was developed. The research data gathered in four years of the Project gives an opportunity to draw some conclusions on asphalt pavement deterioration in Lithuania. This article presents the main HDM asphalt pavement deterioration models, and describes the most important steps in adaptation of some input data to those models and calibration of the models to the local conditions.
\end{abstract}

Keywords: road pavement, pavement condition, deterioration, modelling, testing, calibration, HDM.

\section{Introduction}

Planning of road network maintenance and development activities is closely connected with the need to forecast future road network condition. For this purpose pavement performance models are used and often integrated into more complex computing systems as pavement management systems (PMS). Currently there are three systems modelling pavement deterioration and used in Lithuania (Transport and Road Research Institute TRRI): HDM-III, HDM-4 and DAVASEMA - Lithuanian pavement management system developed by Lithuanian Road Administration and based on HDM-III pavement deterioration and road user effect models. The pavement deterioration models are based on research conducted mainly in the countries of South America and Asia. That's why local adaptation of HDM pavement deterioration models is always desirable to reflect differences in weather conditions, construction materials, methods, etc.

Since the pavement deterioration model simulates future changes in the pavement condition, the model application involves two important steps:

- Adaptation of the input data - a correct interpretation of the input requirements, and achieving a quality of input data that are appropriate to the desired reliability of the results;

- Calibration of outputs - adjusting the model parameters to enhance how well the forecast and outputs represent the changes and influences over time and over various interventions [1].
In 1997, Lithuanian Road Administration and Transport and Road Research Institute executed Lithuanian Road Pavement Deterioration Research Project. The Project was designed to cover the above-mentioned steps of application of HDM pavement deterioration models. The research data gathered in four years of the Project give an opportunity to do some conclusions on asphalt pavement deterioration trends in Lithuania [2].

\section{Adaptation of input data}

Within the Project during the period from 1997 to 2000 the deterioration of 35 experimental road sections located on main and national roads was investigated. The following sections were selected:

- Newly constructed road sections, opened for traffic 1-2 years having no pavement defects; traffic volume on these sections can be estimated from the initial stage;

- Road sections where 1-2 years ago pavement rehabilitation was carried out by levelling the existing pavement and placing an asphalt concrete overlay; traffic volume can be estimated from the time the pavement has been rehabilitated.

The length of each section $-300 \mathrm{~m}$. Type of the pavement - asphalt concrete on granular base. Other main features - thickness of layers, construction age, traffic loading, etc, more or less differ from section to section [3]. 
According to Bennett and Paterson [1] and as it is considered in HDM pavement deterioration models, the main pavement characteristics the pavement deterioration depends on are as follows:

- Pavement structural condition expressed by the modified structural number $S N C$ (in HDM-4 the influence of $S N C$ data precision on sensitivity of pavement deterioration prediction is described by highest sensitivity class S-I and impact elasticity $>0,5$ );

- Pavement (initial) roughness expressed by International Roughness Index, IRI (sensitivity class S-I, impact elasticity $>0,5$ );

- Traffic loading expressed by the number of equivalent 8,2 t standard axle loads ESAL's (sensitivity class $\mathrm{S}-\mathrm{II}$, impact elasticity $0,2-0,5$ );

- Construction and pavement age (sensitivity class S-II, impact elasticity $0,2-0,5$ );

- Cracking area (sensitivity class S-II, impact elasticity $0,2-0,5)$.

Consequently these are the main pavement parameters monitored during pavement deterioration research.

Pavement roughness IRI was measured by car mounted laser profilometer "Dynatest 5051 RSP" twice a year. Data on cracking area and other pavement defects were gathered during visual inspections of the test sections at least once a year. For estimating traffic loading data, traffic flow composition and values were used. These data were obtained from traffic counting posts installed on those roads where the test sections are located.

The estimation of the pavement structural condition SNC is much more complicated than of other parameters. Nowadays the most common means to rapidly and economically estimate pavement's $S N C$ is the use of nondestructive testing with FWD. There are several inadequate methods for calculating $S N C$ from FWD deflection testing results, but any of these methods can be used without estimating local conditions. Thus the main problems of applying FWD measurements for prediction of $S N C$ are:

- selection of the right $S N C$ calculation method and adaptation of it to the local conditions and needs;

- collection of additional road pavement data with appropriate quality for that method.

\subsection{Deflection measurements and calculation of mea- surement data}

Dynamic deflections of the road pavement were measured by the Falling Weight Deflectometer Dynatest 8000 FWD. They were taken on both traffic lanes of each test section by measuring two test points of each traffic lane (four points on each test section). During testing the load of $40 \mathrm{kN}$ is applied on the road pavement. Deflections are recorded by 9 sensors (geophones; spacing of sensors from the centre of the loading plate are: 0,200 , $300,450,600,900,1200,1500,1800 \mathrm{~mm})$. The average number of 14 measurements were taken annually in each test section. The schedule of testing was based on climatic conditions (in summer - once per month, during spring thaw - once per week, no measurements were carried out in winter time). When measuring deflections, the asphalt concrete pavement temperature at a depth of the half of the total asphalt concrete thickness was measured too. It was used for determining a temperature adjustment factor required for calculating pavement deflection values at an assumed reference temperature of $20{ }^{\circ} \mathrm{C}[4]$

Received deflection values were then recalculated at $708 \mathrm{kPa}$ pressure, corresponding to the load of $50 \mathrm{kN}$. It was done with assumption that the relationship between deflection and loading is linear $[5,6]$.

The modified structural number $S N C$ is defined as:

$$
\begin{gathered}
S N C=S N+S N S G ; \\
S N=\sum_{i=1}^{\text {nlaver }} a_{i} h_{i} ;
\end{gathered}
$$

$S N$ - structural number of all pavement layers; nlayer number of layers above the subgrade; $a_{i}$ - layer coefficient of layer $i ; h_{i}$ - thickness of layer $i$ (in); SNSG structural number contribution from the subgrade:

$$
S N S G=3,51 \log (C B R)-0,85(\log (C B R))^{2}-1,43 ;(3)
$$

$C B R$ - California Bearing Ratio:

$$
\log (C B R)=3,264-1.018 \log \left(D_{900}\right) ;
$$

$D_{900}$ is deflection of $900 \mathrm{~mm}$ from the centre of loading plate (microns).

It is possible to calculate $S N C$ from FWD data straight from the definition given above (equations 1,2 ). For this purpose pavement layer coefficients and SNSG are needed. In this case pavement layer coefficients $a_{i}$ are derived from resilient modulus of each pavement layer above the subgrade $E_{i}$ and $S N S G$ is derived from the roadbed deformation modulus $E_{g}$. This is called AASHTO NDT Method I [5]. Calculations of $E_{i}$ and $E_{g}$ were carried out by using ELMOD (Evaluation of Layer Modulus and Overlay Design) software designed and supplied by the DYNATEST. The software enables to calculate resilient modulus of each layer in the pavement structure of two, three or four layers by using Odemark Boussinesq transformed cross-sectional method [7].

When no data on pavement layer thickness is available or its accuracy is questionable for calculation of SNC for applying in HDM-III or HDM-4, it is recommended to use the equation developed by G. W. Jamesons $[8,9]$ :

$$
S N=1,69+\frac{842,8}{D_{0}-D_{1500}}+\frac{42,94}{D_{900}} .
$$

$D_{0}$ is peak deflection (microns); $D_{1500}$ - deflection of $1500 \mathrm{~mm}$ from the centre of loading plate (microns).

Besides AASHTO NDT Method I (backcalculation of layer moduli) and Jamesons method in the initial stage of the Project other AASHTO method known as NDT 
Method II [5] was also used for calculating $S N C$. This method is recommended for design of pavement structures, and the AASHTO procedure for evaluation of pavement strengthening needs is adopted in Lithuania. Though statistical analysis of $S N C$ results calculated by these three methods has confirmed the conclusions done by NDLI while performing the comparison of the same methods in 1995 [8] - none of any two of these methods gives an ideal linear correlation. Linear correlation results between calculated $S N C$ received by TRRI:

- AASHTO NDT Method I (backcalculation of layer moduli) vs NDT Method II - 0,85 (0,84 according to NDLI [8]);

- AASHTO NDT Method I (backcalculation of layer moduli) vs Jamesons method - 0,92 (0,84 according to NDLI [8]);

- AASHTO NDT Method II vs Jamesons method $0,76(0,75$ according to NDLI [8]).

Taking into account these results and the following:

- AASHTO NDT Method I (backcalculation of layer moduli) is considered as the most accurate means for estimating layer modulus, but it requires accurate data on pavement layer thicknesses;

- Jamesons method is simple and needs only deflection data for calculating $S N C$;

- for further $S N C$ estimations the choice was made on Jamesons method.

\subsection{Analysis of changes in structural condition due to seasonal factors}

The decrease in pavement structural condition on each test section due to seasonal factors (ie critical period adjustment factors) is determined by comparing the maximum and the minimum values of pavement structural condition, measured during the three-year research on each test section [10].

The seasonal factors were determined according to the data of a specific year of research. The following criteria of pavement structural condition were used:

- The equivalent resilient modulus of the all pavement layers above the subgrade, $E_{e k v}$;

- Deformation modulus of the roadbed soil, $E_{g}$;

- Pavement structural number, $S N$;

- Subgrade structural number, $S N S G$;

- A modified structural number, $S N C$.

In the course of work the structural condition values of spring and autumn were determined. The results show that in spring pavement structural condition weakens in respect of all criteria, therefore only the structural condition values of spring were used for further analysis [10].

The seasonal tests of pavement deflections show that:

- Under Lithuanian conditions the critical period for pavements is March-April, when the frozen ice crystals thaws from the roadbed.

- A stable period of pavement structural condition is usually observed in a summer period (June - August).

- The calculated seasonal factors for $E_{e k v}, E_{g}, S N$, SNSG, SNC are different.

Based on the three-year research results, the values of seasonal factors were determined for the above-mentioned values (Table), which are the difference between the average spring value and the value of standard deviation.

For further development of the Project it was recommended:

- to measure pavement deflections during the stable summer period, since the seasonal factors are calculated as the ratio between the value of structural condition factor during the most critical period and its value during the stable period;

- when calculating $S N, S N S G$ and $S N C$ used by HDMIII, HDM-IV and the Lithuanian PMS DAVASEMA to take the seasonal factors into account.

\section{Adaptation of HDM asphalt pavement deteriora- tion models}

There are three levels of calibration and adaptation for HDM as a whole and for HDM asphalt pavement deterioration models as well [1]:

1) Basic application - determines the values of required basic input parameters, adopts many default values, and calibrates the most sensitive parameters with best estimates, desk studies or minimal field surveys.

2) Calibration - requires measurements of additional input parameters and moderate field surveys to calibrate key predictive relationships to local conditions. This level may entail slight modification of the model source code.

3) Adaptation - undertakes major field surveys and controlled experiments to enhance the existing predictive relationships or to develop new and locally specific

Critical period adjustment factors for each pavement structural condition parameter [10]

\begin{tabular}{|l|c|}
\hline \multicolumn{1}{|c|}{ Pavement structural condition } & Critical period adjustment factor \\
\hline The equivalent resilient modulus of the road pavement, Eekv & 0,58 \\
\hline Deformation modulus of the roadbed soil, $E g$ & 0,74 \\
\hline Pavement structural number, $S N$ & $\mathbf{0 , 7 3}$ \\
\hline Subgrade structural number, $S N S G ;$ & 0,87 \\
\hline A modified structural number of the road pavement, $S N C$ & 0,77 \\
\hline
\end{tabular}


relationships for substitution in the source code of the model.

Lithuanian Bituminous Pavement Deterioration Research Project is aimed at covering all three levels, but since the amount of data gathered during four years of research on 35 experimental test sections is not enough for adaptating the models (adaptation level) this section focuses on the basic application and calibration of the models.

HDM considers pavement roughness prediction model and pavement cracking initiation and progression models as the main models for prediction of bituminous pavement deterioration rates.

\subsection{Influence of $S N C$ on progression of pavement $I R I$}

While analysing asphalt pavement research data gathered during four years of the Project, first of all it was attempted to derive the magnitude of influence of pavement structural condition given in terms of $S N C$ on the regression of pavement roughness.

Road pavement roughness is defined as irregularities in the pavement surface that cause most concern among road users and that arise from the number of causes, most of which can be predicted [11, 12]. HDM-4 (HDM-III as well) roughness progression model could be expressed by the following equation:

$$
\Delta I R I=\sum_{i=l} \Delta I R I i
$$

$\triangle I R I$ - total increment in $I R I$ in $\mathrm{m} / \mathrm{km}$ during one year; $\Delta I R I i$ - components of different $I R I$ progression causes. There could be structural, cracking, ravelling, rutting, potholing, delamination, patching and environmental components.

It was defined that only structural and environmental components had obvious influence on roughness in the experimental road sections since only minor cracking and rutting and no other defects were observed in the four new pavement years period (actually in three years period, because in most cases the first year of the Project was the year when those sections were paved). So the expressions of structural, cracking, rutting and environmental components have to be introduced in Eq 6:

$$
\begin{aligned}
& \triangle I R I=134 \cdot e^{m \cdot A G E 2}(1+S N C K)^{-5} \cdot Y E 4+ \\
& 0,0066 \cdot \triangle A C A+0,88 \cdot \triangle R D S+m \cdot I R I \cdot \Delta T ;
\end{aligned}
$$

$m$ is environmental coefficient; $A G E 2$ - years since the last resurfacing; $S N C K$ - the modified structural number of the pavement, reduced for the effect of cracking in bituminous layers. If $S N C$ is derived from the field testing, it is assumed as equal to $S N C K ; Y E 4$ - annual axle loading, in million ESAL's per year; $D A C A$ - increment in all cracking, in percent area; $D R D S$ - increment in standard deviation of rut depth, in $\mathrm{mm}$; $I R I$ - roughness of the pavement in the beginning of the year, in $\mathrm{m} / \mathrm{km}$; $D T$ - length of the period considered; in this case - one year.
The main factors in Eq 7 are modified structural number of the pavement $S N C$ (or $S N C K$ ) and annual axle loading YE4. The increment area of all cracking and incremental rutting also depends on these two parameters. So basically the progression of roughness should be closely related to pavement structural condition and traffic loading. Fig 1 shows the relation of the total pavement roughness increment (in term defined as a passage of one million ESAL's) vs SNC derived from the data of the experimental road section surveys. The relationship curve is expressed as a mathematical power function:

$$
Y=a X^{b},
$$

$Y=\Delta I R I / Y E 4 ; \mathrm{m} / \mathrm{km} / \mathrm{mln}$. ESAL's; $\Delta I R I$ - total pavement roughness increment for a road section in the particular year; YE4 - annual axle loading on the particular road section in million ESAL's per year; $X$ - average $S N C$ on the road section in the beginning of the year considered; $b=-5$ assumed according to Eq 7; $a-$ average calibration coefficient for all $n$ test points.

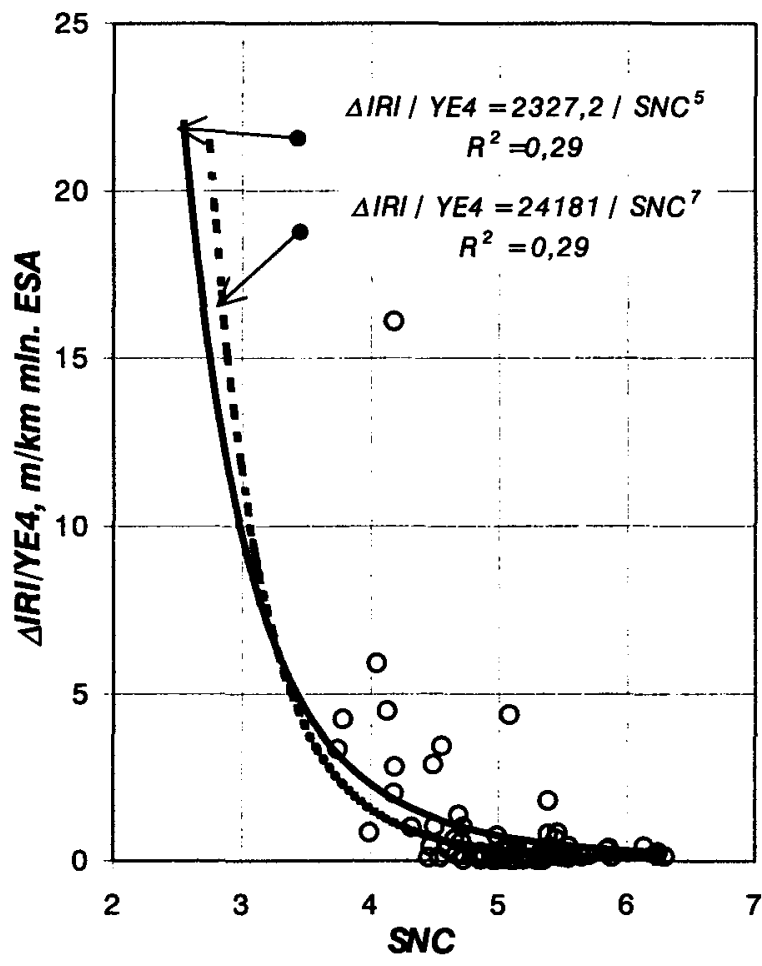

Fig 1. Relation between road roughness increment and $S N C$

\subsection{Evaluation of environmental effect}

The environmental effect on progression of pavement roughness is evaluated by environmental component; the main parameter of that component is environmental coefficient $\mathrm{m}(\mathrm{Eq} 7)$. To determine this coefficient the comparison of the yearly increments in road roughness on the particular test sections and predicted road roughness increment for that particular road section is needed. 
Since the road pavement roughness IRI, modified structural number SNC and other needed parameters are measured during the surveys, then $A I R I$ is the total measured increment in IRI (in $\mathrm{m} / \mathrm{km}$ ) during one year and other incremental values are calculated accordingly. Coefficient $m$ is the only unknown parameter in $\mathrm{Eq} 7$. Though this equation has no mathematical solution, it could be solved by the approach method.

Environmental coefficient $m$ was calculated for one year periods starting from the mid summer of one year to another. The average derived value for the whole test sections in the 1997-2000 year period is $m=0,068$. The HDM recommended $m$ value for Lithuanian climate conditions is $m=0,065$.

\subsection{Calibration of pavement cracking models}

There are three main types of cracking in bituminous pavements: structural, thermal and reflection cracking [13].

As with other distresses in HDM, structural cracking is modelled as having two distinct phases: initiation phase - the time to the development of distress, and the progression phase.

Structural cracking initiation model is an exponential relationship between traffic loading and $S N C$ of road pavement [13]:

$$
I C X=K i c \cdot\left[a 0 \cdot \exp \left(a 1 \frac{Y E 4}{S N C^{2}}\right)\right]
$$

$I C X$ is time to structural cracking initiation, in years (it is assumed that the initiation of structural cracking is a moment in time when $0,5 \%$ of road pavement is cracked); $a 0, a l$ - coefficients for which default values dependent on road pavement type can be adjusted; Kicx - model calibration parameter.

Structural cracking initiation model with default parameters and applicable to Lithuanian conditions (Fig 2):

$$
I C X=K i c x\left[8,61 \cdot \exp \left(-24,4 \begin{array}{c}
Y E 4 \\
S N C^{2}
\end{array}\right)\right] ;
$$

Structural cracking progression model initially was defined by Peterson [14]. It predicts increment in indexed structural cracking of bituminous pavements:

$$
C R X_{t}=K c p\left\{50(1-Z)+Z\left[\begin{array}{l}
Z \cdot a 0 \cdot a 1 \cdot N E c i+ \\
+Z 0,5^{a 1}+(1-Z)^{a 1}
\end{array}\right]^{\frac{1}{a 1}}\right\}
$$

$C R X_{t}$ is incremental area of indexed cracking at time $\mathrm{t}$, in $\% ; z=1$, if $T C I<t_{50}$; otherwise $z=-1 ; T C I$ - time since cracking initiation, in years; $N E C i$ - cumulative traffic loading since the initiation of cracking, ESAL's; $t_{50}-$ time to $50 \%$ of structural cracking appear: $t 50=50^{a}{ }_{-}$ $0,5^{a 1} / a 0 a 1 ; a 0, a 1$ - default coefficients; $K c p$ - model calibration parameter.

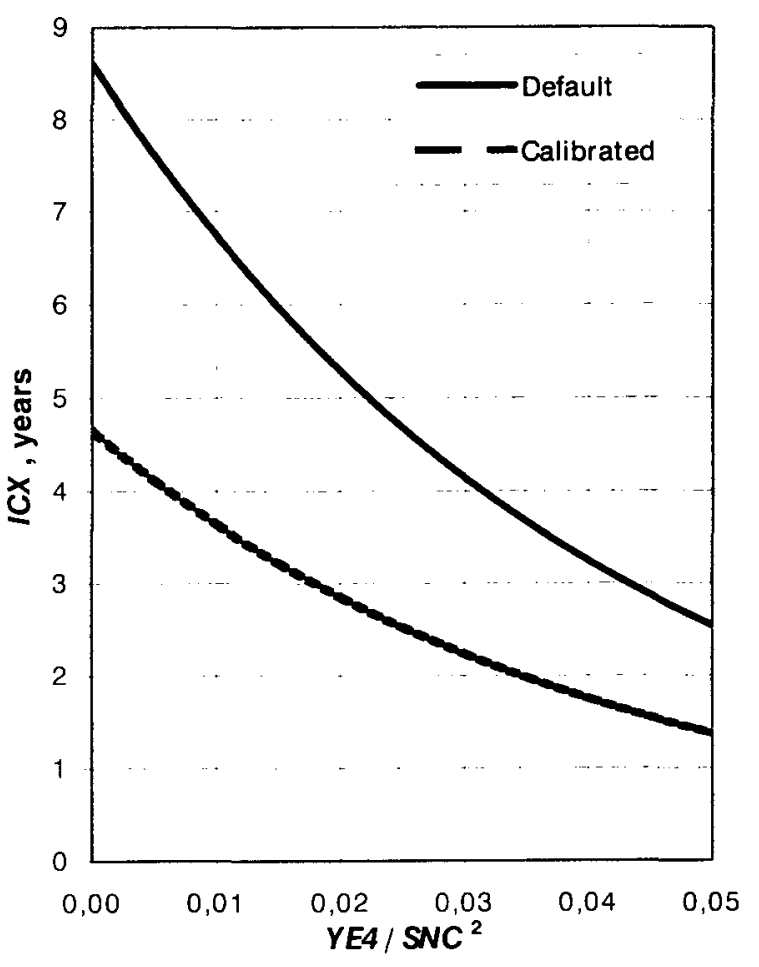

Fig 2. Default and calibrated HDM structural cracking initiation models

For model simplification it is better to analyse structural cracking progression till the moment when $50 \%$ of structural cracking appears (though such amount of cracking is not likely to appear on maintained pavement). Then $T C I<t_{50}, \mathrm{z}=1$ and:

$$
C R X_{t}=K c p\left[a 0 \cdot a \mathrm{l} \cdot N E c i+0,5^{a 1}\right] \frac{1}{a 1} .
$$

After introduction of default parameters for Lithuanian conditions (Fig 3):

$$
C R X_{i}=K c p\left[0,25 \cdot 3330 \frac{N E c i}{S N C^{4,25}}+0,5^{0,25}\right]^{4} \text {. }
$$

Thermal cracking model. As considered by NDLI [8], thermal cracking is primarily a function of material and environmental factors and they initiate immediately after construction or repaving. Odoki \& Kerali [15] propose an assumption that in countries with climatic conditions similar to Lithuanian (sub-humid temperate cool / temperate freeze) thermal cracks appear next year after paving - time to cracking initiation is $\mathrm{ICT}=1$ year. Then thermal cracking progression model is:

$$
\begin{aligned}
& d N C T=K c p t\left(\begin{array}{c}
1 \\
C D S
\end{array}\right) \times \\
& \left\{0 ; M I N\left[\left[\begin{array}{c}
(N C T e q-N C T a) ; \\
2 N C T e q(A G E 3-I C T-0,5) \\
T e q^{2}
\end{array}\right)\right]\right\} d t
\end{aligned}
$$

$d N C T$ is increment in cracking intensity expressed as the 


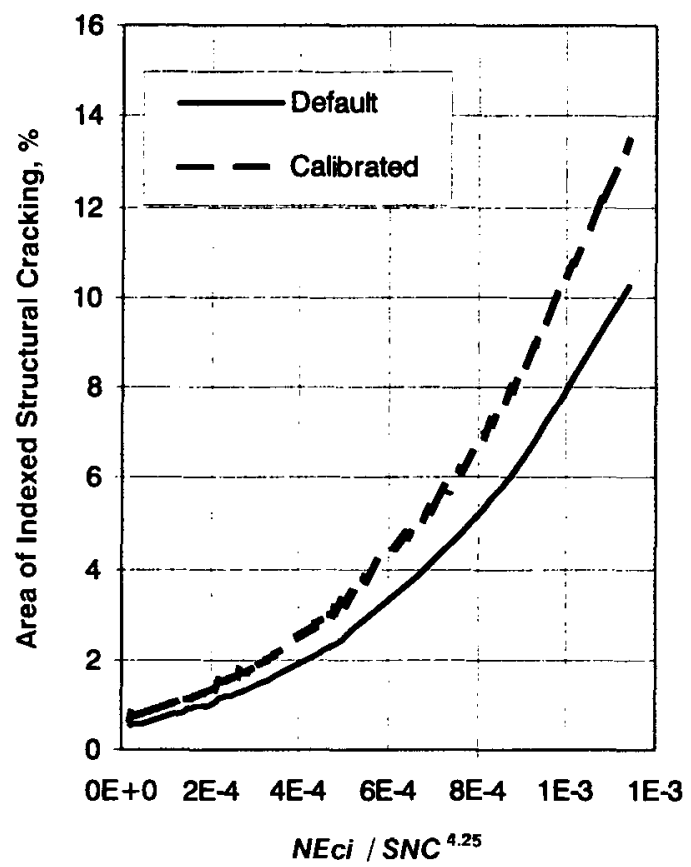

Fig 3. Default and calibrated HDM structural cracking progression models

number of crack per kilometer during one year or time period $d t$, number $/ \mathrm{km}$. Again the assumption is made that thermal cracks all are transverse cracks. Then $d N C T$ can be derived from the total amount of transverse cracks on the road section: $N C T=20 A C T$ or $d N C T=20 \mathrm{dACT}$; $d t$ - duration of the period to be modelled, years. Since thermal cracking model is incremental model, it is considered as $d t=1 ; A G E 3$ - pavement age since the last reconstruction, years; $C D S$ - construction defects or cracking prevention method indicator; if none of these available $C D S=1$; NCTa - number of (reflected) transverse thermal cracks at the start of the analysis year, number $/ \mathrm{km}$; NCTeq - maximum number of thermal cracks per $\mathrm{km}$, for climate conditions similar to Lithuanian recommended $N C T e q=201 / \mathrm{km}$ [15]; Teq - time since initiation to reach maximum number of thermal cracks, years; recommended $T e q=7$ years [15]; Kcpt - model calibration factor.

In $\mathrm{Eq} 15$, maximum and minimum limitations are used to avoid predicted intensity of cracking exceed maximum of cracking intensity allowed NCTeq. When this condition is ensured and $I C T<A G E 3 \leq(I C T+T e q)$, the equation can be simplified:

$d N C T=K c p t \frac{1}{C D S}\left(\frac{2 \cdot N C T e q \cdot(A G E 3-I C T-0,5)}{T e q^{2}}\right) d$.

With default values:

$$
d N C T=K c p t \frac{1}{C D S}(0,816 \text { AGE3-1,224). }
$$

This simplification allows to deduce absolute (non incremental) model for thermal cracking (Fig 4).

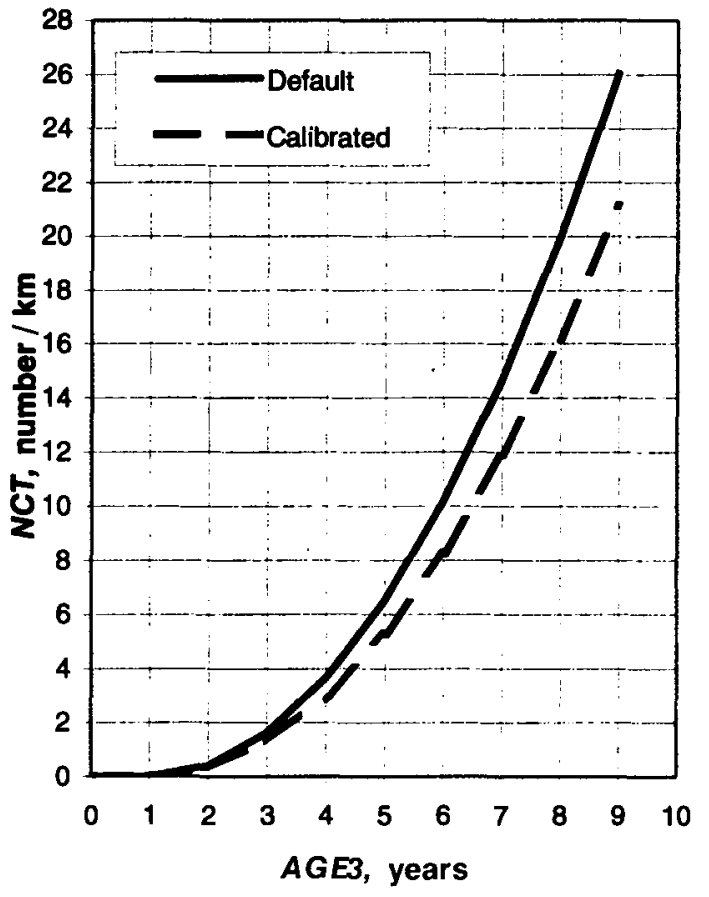

Fig 4. Default and calibrated HDM thermal cracking progression models

The total thermal cracking area $N C T$ at the time moment $t$ is equal to the sum of all thermal cracking increments $d N C T$ since its initiation $N C T=\sum_{i=1}^{n} d N C T_{i}$ and:

$$
N C T=\sum_{i=2}^{n} K c p t \frac{1}{C D S}\left(0,816 \mathrm{AGE}_{i}-1,224\right) ;
$$

$i$ changes from 2 to $n$, because of the assumption that thermal cracking initiates in the second year after paving. Then $A G E 3$, can be replaced by $i+I C T$ or $i+1$, and $=0,5\left(n^{2}+n\right) ; n=A G E 3$. It leads to the final simplification of the equation:

$$
N C T=K c p t \stackrel{1}{C D S} 0,408 A G E 3^{2} .
$$

Calibration of cracking models was done by adjusting calibration factor $K$. This factor was calculated for each pavement test section where a particular type of cracking was observed. The obtained research data sample (mathematical) was insufficient for statistical selection, thus average $K$ value for all road sections was calculated.

Calibration factor $K$ was calculated as a ratio of the cracking parameter value observed on the test section against the predicted value of a particular cracking parameter for the particular road section and conditions. Here are average calibration factors derived for Lithuanian conditions for:

- structural cracking initiation $K i c x=0,55$ (correlation $R=0,44$; standard deviation $S=0,14$ ); 
- structural cracking progression $K c p=1,30$ (correlation $R=0,67$; standard deviation $S=0,76)$;

- thermal cracking progression $K c p t=0,81$ (correlation $R=0,68$; standard deviation $S=0,63$ ).

\section{Conclusions}

1) The pavement seasonal structural condition analysis led to the adaptation of a new methodology for calculating pavement structural condition parameters $E_{e h \nu}$, $E_{g}, S N, S N S G, S N C$. The methodology is based on recalculation of current pavement structural condition value (as measured) to the critical condition value predicted during spring thaw.

2) The derived environmental coefficient $m$ and other pavement deterioration model calibration coefficients show that:

- environmental impact on pavement roughness progression is about the same as that predicted by the authors of HDM-4 for climatic conditions similar to Lithuanian;

- structural cracking appears earlier and develops more rapidly than it is predicted by HDM pavement deterioration models for Lithuanian climatic conditions;

- thermal cracking develops slightly slower than it is predicted by HDM pavement deterioration models for Lithuanian climatic conditions.

3) The derived relation between pavements structural condition SNC and the change in road roughness per 1 million ESAL's shows that the influence of SNC on this relation could be apprised by the power from 5 to 7 .

4) Although the adopted and calibrated HDM pavement deterioration models described in this article are not of high reliability, in the meanwhile they are recommended for predicting asphalt pavement deterioration rates on Lithuanian roads.

5) The calibration factors of the models tend to be more reliable with the further development of the Project and with more research data available. Hopefully this will lead to introduction of the more reliable and accurate pavement deterioration models in the near future.

6) The presented data calculation and model calibration methodology is inconclusive yet and will be put under further refinement as well.

\section{References}

1. Bennett C. R., Paterson W. D. O. HDM-4. Vol 5. A guide to calibration and adaptation. PIARC, 1999. $198 \mathrm{p}$.

2. Puodžiukas V., Kamaitis Z. Strengthening of asphalt pavements and modelling of the strengthening influence on road roughness. Civil Engineering (Statyba). Vol 5, No 6, 1999, p. 386-393 (in Lithuanian).

3. Tebodin consultants and engineers O'Sullivan and Graham. Enhancement of the DAVASEMA pavement management system. Pavement performance modelling. Technical Assistance to Lithuanian Road Administration, 1996. $43 \mathrm{p}$.

4. Baltzer S, Jansen J. M. Temperature correction of Asphalt moduli for FWD measurements. In: Proc. of the 4th international conference on the bearing capacity of roads and airfields. University of Minnesota, 1994. V 1, p. 754-767.

5. AASHTO Guide for design of pavement structures. Washington: AASHTO, 1993. $560 \mathrm{p}$.

6. TRRI. Enhancement of pavement management system. Development of road maintenance economic evaluation subsystem, etc. (Dangu valdymo sistemos tobulinimas. Keliu priežiūros darbų ekonominio pagrindimo posistemio dangu valdymo sistemoje sukūrimas ir t. t.) Kaunas: Transport and Road Research Institute, 1999. 51 p. (in Lithuanian).

7. Per Ullidtz. Modelling flexible pavement response and performance. Polyteknisk Forlag, Gylling, 1998. 205 p.

8. NDLI. Modelling road deterioration and maintenance effects in HDM-4. Vancouver: N.D. Lea International, 1995. $220 \mathrm{p}$.

9. TRB (Transportation Research Board). Transportation research record No 1397. Pavement management systems. National Academy press. Washington D.C., 1993. 119 p.

10. Puodžiukas V., Pakalnis A. Determination of seasonal factors for structural condition values of bituminous pavements. Journal of Civil Engineering and Management, Vol VIII, No 2, 2002, p. 133-137.

11. Amy L., Simpson F., William O. Rutting analysis from a different perspective. Transportation research record No 1473. Pavement design, management and performance. National Academy press. Washington D.C., 1995, p. 9-17.

12. Bernard A., Akhtarhusein A., Carl L. Early rutting of asphalt concrete pavement under heavy axle loads in hot desert environment. Transportation research record No 1473. Pavement design, management and performance. National Academy press. Washington D.C., 1995, p. 25-35.

13. Petkevičius K., Sivilevičius H. Necessary characteristics and rational life duration of asphalt pavements and road pavement structures. Transport (Transportas), Vol 15, No 4, 2000, p. 184-195 (in Lithuanian).

14. Peterson W. D. O. Road deterioration and maintenance effects. Models for planning and management. The John Hopkins University Press, Baltimore, 1987. $454 \mathrm{p}$.

15. Odoki J. B., Kerali H. G. R. HDM-4. Vol 4. Analytical framework and model descriptions. PIARC, 1999. $634 \mathrm{p}$. 